\title{
In Situ Polymerase Chain Reaction-based Localization Studies Support Role of Human Herpesvirus-8 as the Cause of Two AIDS-related Neoplasms: Kaposi's Sarcoma and Body Cavity Lymphoma
}

\author{
Kimberly E. Foreman, Patricia E. Bacon, Eric D. Hsi, and Brian J. Nickoloff \\ Skin Disease Research Laboratories, Loyola University Medical Center, Maywood, Illinois 60153-5385
}

\begin{abstract}
Several lines of investigation point to a new herpesvirus, human herpesvirus-8 (HHV-8), as the cause of two different neoplasms seen in AIDS patients-Kaposi's sarcoma (KS) and body cavity $\mathrm{B}$ cell lymphoma. If this virus is the etiological agent, rather than another opportunistic infectious agent, it should be present in the earliest detectable clinical lesions on a temporal basis, and localize to specific target cells in a spatial pattern consistent with tumorigenic pathways. In this study, we take advantage of the clinical accessibility to biopsy early (patch stage) skin lesions of KS to address the temporal issue, combined with in situ PCR and dual immunostaining using a marker identifying malignant cells, to address the spatial localization issue. 21 different tissue samples were subjected to PCR analysis and in situ PCR with and without simultaneous immunostaining. In normal skin from healthy individuals, no HHV-8 DNA was detected by PCR or in situ PCR. However, in all PCR-positive tissues, distinct and specific in situ PCR staining was observed. In four different patch stage KS lesions, in situ PCR staining localized to nuclei of endothelial cells and perivascular spindle-shaped tumor cells. Later stage KS lesions (plaques and nodules) revealed additional positive cells, including epidermal keratinocytes (four of five), and eccrine epithelia (two of four). These patterns were nonrestricted to skin, as pulmonary KS also revealed HHV-8-specific infection of endothelial cells and $\mathrm{KS}$ tumor cells, as well as epithelioid pneumocytes (two of two). In body cavity B cell lymphoma by dual staining, HHV-8 was present in malignant tumor cells (EMA immunostained positive) and not in reactive lymphocytes. These results reveal an early temporal onset and nonrandom tissue and cellular distribution pattern for HHV-8 infection that is consistent with a causal link between this DNA virus and two AIDS-related neoplasms. (J. Clin. Invest. 1997. 99:2971-2978.) Key words: Kaposi's sarcoma - human herpesvirus-8 - in situ polymerase chain reaction - lymphoma $\cdot$ acquired immunodeficiency syndrome
\end{abstract}

\footnotetext{
Address correspondence to Brian J. Nickoloff, M.D., Ph.D., Department of Pathology, Skin Disease Research Laboratories, Loyola University Oncology Institute, Room 301, 2160 South First Avenue, Maywood, IL 60153-5385. Phone: 708-327-3241; FAX: 708-327-3239; E-mail: bnickol@luc.edu

Received for publication 14 October 1996 and accepted in revised form 25 March 1997.
}

J. Clin. Invest.

(C) The American Society for Clinical Investigation, Inc. 0021-9738/97/06/2971/08 \$2.00

Volume 99, Number 12, June 1997, 2971-2978

\section{Introduction}

Epidemiological evidence has long suggested that Kaposi's sarcoma $(\mathrm{KS})^{1}$ has an infectious etiology (1). Recently, studies have documented the presence of short viral DNA sequences in KS lesions that represent a previously unidentified herpesvirus referred to as $\mathrm{KS}$-associated herpesvirus or human herpesvirus-8 (HHV-8) (2-5). This virus, which is homologous to Epstein-Barr virus and herpesvirus saimiri, has been linked to KS by virtue of its presence in $>95 \%$ of all $\mathrm{KS}$ lesions tested with polymerase chain reaction and Southern blot analysis, and by several recent seroepidemiologic studies examining HHV-8specific antibodies in patient and control serum samples (6-9). While these reports vary in the seroprevalence rates for HHV-8 in the general population ( $0-28 \%)$, they consistently found that a majority of KS patients (71-100\%) have HHV-8-specific antibodies, providing evidence, albeit indirect, that HHV-8 may be the cause of KS.

However, as pointed out by others, it is important to go beyond these types of indirect studies that suggest disease association between HHV-8 and KS, to probe deeper into the precise relationship between HHV-8 and human tissues (10-13). Currently, little is known about the cellular and subcellular localization of HHV-8 in neoplastic tissue samples. What has been learned based on our studies, and those of others examining fresh and cultured KS cell lines, is that the HHV-8 genome is present in just one or a few copies per cell (circular, latent form) in KS lesions $(2,14-16)$. Such low copy numbers present a challenge to investigators attempting to define the cellular patterns of infectivity. It becomes critical to use the most sensitive detection system that also preserves tissue architecture to permit definitive conclusions to be drawn. This potential sensitivity problem was noted by $\mathrm{Li}$ et al. (17) using traditional in situ hybridization, since one third of their tissue samples that were PCR positive for HHV-8 were completely negative in tissue in situ hybridization. Thus, in situ hybridization has significant limitations for these types of studies as it is relatively insensitive and cannot detect low copy number DNA that are present in KS (18-20). Boshoff et al. used PCR in situ hybridization to further enhance the tissue localization rates for HHV-8 (21). They demonstrated the presence of HHV-8 in both vascular endothelial cells and spindle-shaped tumor cells, but they only examined late-stage nodules, and not the earlier patch or plaque-stage lesions.

If HHV-8 is the cause of KS, it should be present in the earliest detectable lesions. Examining only late stage lesions does not provide as strong support for establishing causal links as do studies involving lesions that are in their infancy. It has always

1. Abbreviations used in this paper: BCBL, body-cavity based lymphoma; EMA, epithelial membrane antigen; HHV-8, human herpesvirus-8; KS, Kaposi's sarcoma. 
been difficult for investigators studying the etiology of KS to separate preferred viral passengers that represent opportunistic infection from key pathogenic and causal agents. We reasoned that the most compelling argument to link HHV-8 to KS (short of a demonstration that its injection in a suitable animal model produces the disease), was to identify its presence in the earliest detectable clinical lesions. At this stage of the disease, the AIDS patients have significantly less immunosuppression than at the later stages of KS, thereby reducing the chances that this is an opportunistic infection. Another important reason for examining early lesions of KS is that it permits an assessment of the preneoplastic cells that may be caught in the transition to spindle-shaped tumor cells. Perhaps as confusing as identifying the cause of KS has been the historical histogenetic dilemma in defining the precursor cell that gives rise to the KS tumor cell. To address these issues regarding the etiology and pathogenesis of KS, we describe a protocol using in situ PCR. This technique permits the direct visualization of low copy DNA sequences, and we could detect HHV-8 in the patch stage lesions of KS. We demonstrate specific amplification of HHV-8 in patch stage lesions within endothelial cells and perivascular spindle-shaped cells. Thus, the PCR signal detected from patch stage lesions is not coming from circulating B cells replicating HHV-8 trapped in the vessels contained within the biopsy samples. In more advanced skin lesions of $\mathrm{KS}$, we also identified HHV-8 in basal keratinocytes and eccrine epithelium. To determine if this technique would also work at nonskin sites, we used it on pulmonary KS lesions as well, with similar results. Finally, we applied the technique to lesions of another AIDS-related neoplasm, body cavity-based B cell lymphoma (BCBL), and developed the technology further, combining in situ PCR with immunostaining on the same tissue sample. This dual staining revealed that HHV-8 was present in epithelial membrane antigen-positive lymphoma cells, but not reactive lymphocytes (which was confirmed by ultrastructural analysis) (22).

This is the first report to localize HHV-8 in early patch stage KS lesions. We also detected HHV-8 in epithelial type cells, predominantly associated with later stage (i.e., tumors/ nodules) KS disease, and demonstrated that this highly sensitive and specific technique can be used for cutaneous and noncutaneous tissue samples. Determining the range of host cells (both tumorigenic and nontumorigenic) infected with HHV-8, particularly in the early stage lesion, provides important new insight into its etiological and pathophysiological role in $\mathrm{KS}$ and other AIDS-related neoplasms such as BCBL.

\section{Methods}

Tissue samples. Paraffin-embedded tissue samples were retrieved from archival diagnostic specimens. Samples included cutaneous KS lesions (classical KS, $n=1$; iatrogenic KS, $n=3$; AIDS-KS, $n=5$ ), normal human skin $(n=4)$, pulmonary tissue containing nodules of KS from AIDS patients $(n=2)$, and multiple lymphoma tissue samples $(n=8)$ from a patient with AIDS-related BCBL as previously described (22). Cutaneous KS lesions were from patch $(n=4)$ and plaque $(n=2)$, as well as nodular stage lesions $(n=3)$. 5- $\mu$ m-thick sections were cut and placed on silane-coated glass slides for in situ PCR (Perkin-Elmer Cetus Instruments, Foster City, CA). All tissue samples from disease sites were independently confirmed as being HHV-8 positive by conventional PCR techniques, and the normal skin samples were HHV-8 negative using the same methodology as previously described $(2,23)$.
In situ PCR. Direct in situ PCR was performed using modifications of previously published methodology $(21,24,25)$. Briefly, tissue sections were dewaxed with xylene for $30 \mathrm{~min}$ and $100 \%$ ethanol for $5 \mathrm{~min}$. The samples were gradually rehydrated using a graded series of alcohols and digested with $0.02 \mathrm{M} \mathrm{HCl}$ for $10 \mathrm{~min}, 0.01 \%$ Triton $\mathrm{X}-100$ for $90 \mathrm{~s}$, and $0.5 \mathrm{mg} / \mathrm{ml}$ proteinase $\mathrm{K}$ for $20 \mathrm{~min}$ at $37^{\circ} \mathrm{C}$. The samples were washed extensively in PBS to inactivate the enzyme. For some samples, as indicated in the text, a limited digestion using 1 $\mathrm{mg} / \mathrm{ml}$ trypsin for $40 \mathrm{~min}$ at $37^{\circ} \mathrm{C}$ and a 20 -min incubation in 50:50 methanol:3\% hydrogen peroxide solution was also used. The slides were dehydrated in a graded series of alcohols and their PCR amplification was performed using the GeneAmp in situ PCR 1000 system (Perkin-Elmer Cetus Instruments). Reaction conditions consisted of $1 \times$ PCR buffer II (Perkin-Elmer Cetus Instruments), $1 \mu \mathrm{M}$ of each primer (HHV-8-A 576 TCT GTG CAT GCC CAC GTT CAC C; HHV-8-B ${ }_{576}$ TGC AGC GCG TGG AGC AAT TC), $200 \mu \mathrm{M}$ dNTPs, $20 \mu \mathrm{M}$ digoxigenin-11-dUTP (Boehringer Mannheim Biochemicals, Indianapolis, IN), $4.5 \mathrm{mM} \mathrm{MgCl}_{2}$, and $10 \mathrm{U}$ Taq IS (Perkin-Elmer Cetus Instruments). The slides were assembled using the in situ PCR 1000 slide assembly unit (Perkin-Elmer Cetus Instruments). This unit warms the slide to $70^{\circ} \mathrm{C}$ in order for hot start PCR to be performed. $60 \mu \mathrm{l} \mathrm{PCR}$ reaction mixture (prewarmed to $70^{\circ} \mathrm{C}$ ) was placed directly on the tissue section and covered with a silicon-rubber AmpliCover disc (Perkin-Elmer Cetus Instruments), which was held firmly in place with an AmpliCover clip (Perkin-Elmer Cetus Instruments). The slides were transferred to the GeneAmp in situ PCR 1000 thermal cycler (Perkin-Elmer Cetus Instruments), and then cycled as follows: $92^{\circ} \mathrm{C}$ for $3 \mathrm{~min}(1 \mathrm{cycle})$, followed by $92^{\circ} \mathrm{C}$ for $1 \mathrm{~min}, 65^{\circ} \mathrm{C}$ for $1 \mathrm{~min}$, and $72^{\circ} \mathrm{C}$ for $1 \mathrm{~min}$ (40 cycles). Control reactions used for each sample included reaction mixtures without Taq polymerase and/or primers as well as tissue samples from healthy normal donors that were processed identically to the diseased tissue samples.

AmpliCover clips and discs were removed and the tissue fixed in 95 and $100 \%$ ethanol. The tissue was rehydrated in PBS for $5 \mathrm{~min}$ and soaked in $0.1 \mathrm{M}$ Tris, $\mathrm{pH} 7.5$, and $0.15 \mathrm{M} \mathrm{NaCl}$ (buffer 1) (24). The samples were blocked for $30 \mathrm{~min}$ in buffer 1 containing $2 \%$ fetal bovine serum and $0.3 \%$ Triton X-100 (blocking buffer). The samples were then incubated for $1 \mathrm{~h}$ with anti-digoxigenin-alkaline phosphataseconjugated Fab antibody fragments (1:2,000 dilution; Boehringer Mannheim Biochemicals) prepared in blocking buffer. The slides were washed twice in buffer 1, and then once in $0.1 \mathrm{M}$ Tris, $\mathrm{pH} 9.5,0.1 \mathrm{M}$ $\mathrm{NaCl}$, and $50 \mathrm{mM} \mathrm{MgCl}_{2}$ (buffer 2) for 5 min each. Freshly prepared NBT/BCIP (Sigma Chemical Co., St. Louis, MO) was used as the chromogenic substrate. Slides were generously covered with the substrate and monitored for color development. The reaction on all slides was stopped by washing the slides in TE buffer when the positive control developed a clear signal. Slides were then mounted with Aquamount and examined without additional counterstaining. Slides were examined and photographed using a Provis AX-80 microscope (Olympus Corp., Melville, NY) and IPLab Spectrum scientific imaging software (Signal Analytics Co., Vienna, VA).

In some experiments, slides were processed for detection of $\beta$-globin as described above with the exception of the primers used ( $\beta$-globin$\mathrm{A}_{110}, 5^{\prime}$-CAA CTT CAT CCA CGT TCA CC- $3^{\prime}$; $\beta$-globin- ${ }_{110}$, 5'-ACA CAA CTG TGT TCA CTA GC-3'), and the amplification conditions were modified to $45 \mathrm{~s}$ at $92^{\circ} \mathrm{C}, 45 \mathrm{~s}$ at $58^{\circ} \mathrm{C}$, and $45 \mathrm{~s}$ at $72^{\circ} \mathrm{C}$ for 40 cycles. Studies were also performed using PCR in situ hybridization using similar conditions as described by Boshoff et al. (21). While the two techniques yielded similar results with respect to endothelial cells and spindle-shaped tumor cells, the signal was weaker in some cases using PCR in situ hybridization than was seen in the in situ PCR procedure, and additional positive cell types (i.e., epithelioid cells) were identified using the in situ PCR protocol.

Immunofluorescent staining. In some experiments, after development of the NBT/BCIP color reaction, the tissue sections were dual labeled using fluorescein-conjugated antiepithelial membrane antigen (EMA) (1:10 dilution; Dako Corp., Carpinteria, CA). The slides were washed once in FA buffer (Difco Laboratories Inc., Detroit, 
MI), incubated for 30-45 min with the antibody, and then washed twice with FA buffer before mounting with $90 \%$ glycerol containing $10 \mathrm{mg} / \mathrm{ml} p$-phenylenediamine. Slides were examined and photographed using a Provis AX-80 microscope.

\section{Results}

Cutaneous Kaposi's sarcoma. Initial experiments were performed on advanced KS skin lesions to confirm and extend the previously published results $(17,21)$. Our studies using both in situ PCR and PCR in situ hybridization also demonstrated positive signals for HHV-8 in the spindle-shaped KS tumor cells as well as in the vascular endothelial cells of nodular, late stage KS lesions (data not shown). However, using in situ PCR, we were able to demonstrate the presence of HHV-8 in spindle-shaped tumor cells and endothelial cells in the earliest patch-stage (Fig. 1, $A$ and $B$ ) as well as plaque-stage (Fig. $1 E$ )
KS lesions, which had not been previously described. The spindle cells in early cutaneous KS lesions were clearly positive under the more stringent digestion procedure $(\mathrm{HCl}$ and proteinase $\mathrm{K}$ as described in Methods); however, the morphology was compromised under these conditions. The tissue architecture was better preserved when the digestion conditions were limited to trypsin (as described in Methods), and, under these conditions, endothelial cells as well as some spindle cells were positive (Fig. 1, $A$ and $B$ ) (21). Using both the digestion conditions, the positive HHV-8 signal was localized in the nuclei of these cells. Cells were considered positive when the nuclei acquired a dark purple color. Also, the dermis of normal human skin from HIV-1-negative individuals processed with HHV-8 primers showed no evidence of HHV-8 infection (Fig. $1 C$ ). Note that no counterstaining of the tissue sections was performed to eliminate confusion of hematoxylin-type staining of nuclear DNA. No difference in the staining of these cell types

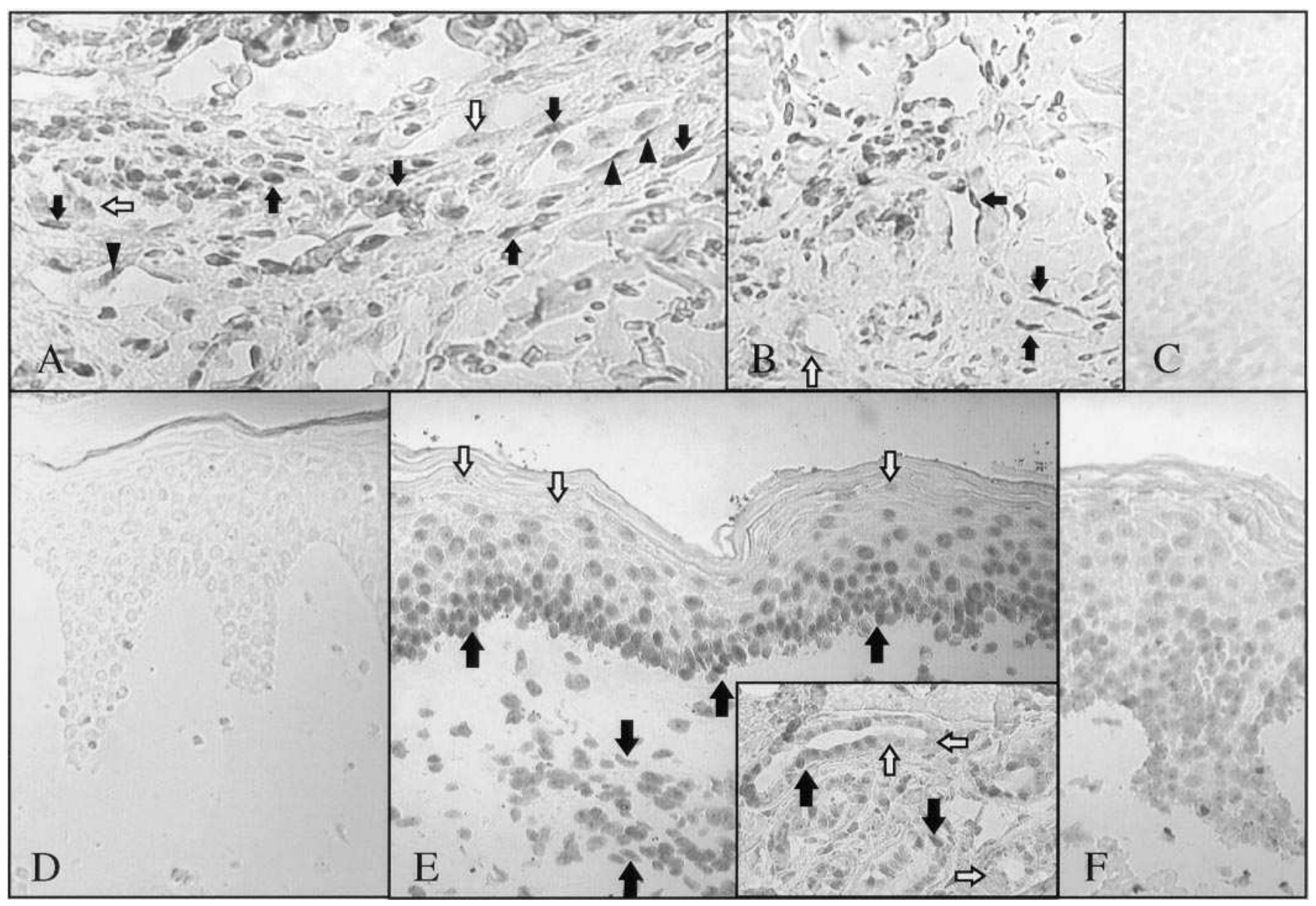

Figure 1. Detection of HHV-8 in cutaneous KS lesions using in situ PCR. (Biopsies were stained to detect HHV-8 as described in Methods. Positive cells are identified by nuclei that have become deep purple after exposure to the NBT/BCIP chromagen. Note that no counterstain is used in any of the tissue sections.) (A) Early patch-stage KS lesion demonstrating that both the spindle-shaped tumor cells and endothelial cells are positive for HHV-8 (solid arrows, spindle-shaped cells; arrowheads, endothelial cells). Some of the endothelial cells were negative for HHV-8 (open arrows). (B) Patch-stage KS lesion from a different patient also showing positive endothelial cells and KS spindle cells (solid arrows, interstitial spindle-shaped cells in lower right; center arrow, endothelial cells). A negative endothelial cell is also highlighted (open arrow). (C) Normal human skin processed as $A$ and $B$ shows no positive staining for HHV-8 in the dermis. $(D)$ Epidermis of normal human skin from healthy adults shows no positive signal for HHV-8. (E) Cutaneous plaque of KS in which the epidermis directly overlying the KS reveals a specific positive signal in basal keratinocytes (upper level, solid arrows), as did the underlying spindle-shaped tumor cells (lower level, solid arrows). Negative keratinocytes near the stratum corneum are also indicated (open arrows). The epithelial cells lining the eccrine ducts in KS lesions also stained positive for HHV-8 ( $E$, inset). Several positive epithelial cells are indicated with closed arrows, while open arrows highlight negative cells. $(F)$ Perilesional skin from the same sample as in $E$. There is little to no specific positive staining for HHV-8 in the basal keratinocytes. 
was found among KS lesions from classic, iatrogenic, or AIDSrelated cases (data not shown).

Interestingly, we also detected HHV-8 in the basal keratinocytes in the area immediately above some of the later stage (i.e., plaque/tumor) KS lesions (four of five), which has not been previously reported (Fig. $1 E$ ). In contrast, such epidermal keratinocyte reactivity was seen in only one of four patchstage lesions. In one sample where there was ample adjacent uninvolved tissue, the positive keratinocytes were concentrated in the area immediately above the lesion (Fig. $1 E$ ), but there was no positive signal in the epidermal keratinocytes in the perilesional skin (Fig. $1 F$ ). The epidermis of normal human skin processed with HHV-8 primers showed no evidence of HHV-8 infection (Fig. $1 \mathrm{D}$ ). As with spindle-shaped tumor cells and endothelial cells within the KS lesion, the signal in basal keratinocytes was largely limited to the nuclei of the cells. Some nuclei in basal keratinocytes, as well as cells of adjacent tissue, were negative, indicating that these signals are specific and not due to leakage of PCR product from sites of amplification to adjacent areas (21). In addition to the positive keratinocytes, endothelial cells, and tumor cells, two of four cutaneous lesions containing eccrine ducts were positive for
HHV-8 (Fig. $1 E$, inset). The signal was localized in the nuclei of the cuboidal epithelial cells lining the ducts.

Control slides were run to confirm that the positive signal in KS skin was indeed specific. As previously mentioned, normal human skin was processed for the presence of HHV-8 using identical conditions as in testing of KS tissue. There was no evidence of specific amplification, as demonstrated in Fig. 1, $C$ and $D$. KS tissue was also processed in the absence of Taq polymerase and/or primers in the PCR reaction mixture to eliminate false positive results based on nonspecific pathways of PCR amplification (25). In all control cases, there was no specific amplification signal (data not shown). However, on the no primer control slides there was occasionally a pale gray or purple staining across the entire tissue section that was clearly nonspecific.

Pulmonary $K S$. To extend our findings in the skin, tissue samples from pulmonary KS cases were examined with in situ PCR for HHV-8. Spindle-shaped tumor cells in the tumorbearing connective tissue surrounding the lung (i.e., pleura) were clearly positive for HHV-8 (Fig. $2 \mathrm{~A}$ ). The endothelial cells lining some of the pulmonary vasculature were also positive for HHV-8 (Fig. 2, $B$ and $C$ ), as were the epithelioid cells

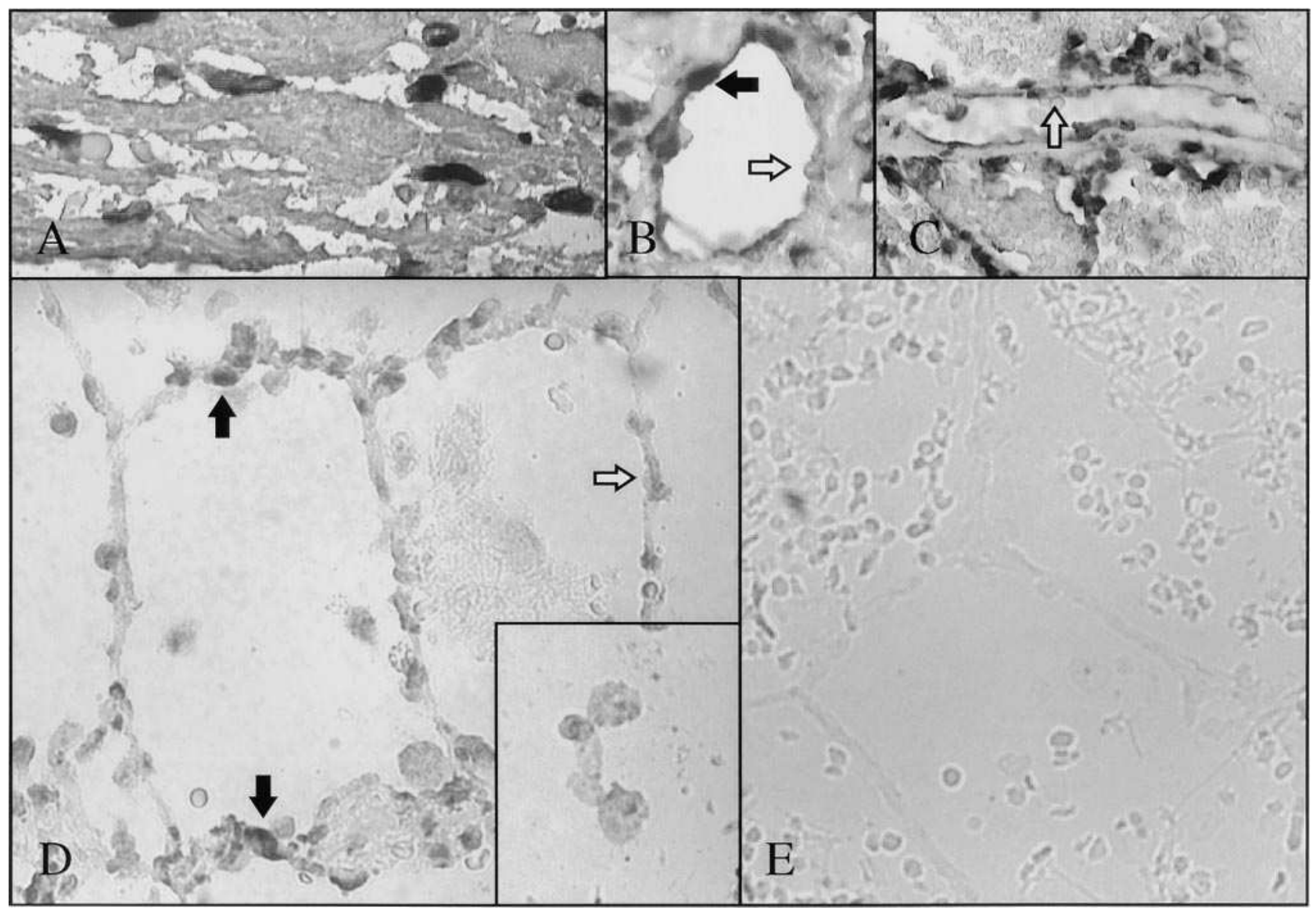

Figure 2. Pulmonary KS tissue samples processed for in situ PCR in the presence or absence of $\mathrm{HHV}-8$ primers ( $\mathrm{HCl}$ and proteinase $\mathrm{K}$ digestion conditions). (A) Spindle-shaped tumor cells in the pleural tissue were positive for HHV-8. (B) Endothelial cells lining some of the pulmonary vasculature were positive for HHV-8 (solid arrow) while other endothelial cells were negative (open arrow). $(C$ ) Endothelial cells lining other vessels in the same tissue section were negative for HHV-8 (open arrow). (D) Cells lining the alveolar spaces could be distinguished as the protuberant (i.e., epithelioid cells) were positive, while the flat-lining cells were HHV-8 negative. Also, the pulmonary macrophages within the alveoli were negative $(D$, inset). (E) Pulmonary KS tissue processed in the absence of HHV-8 primers as a negative control. There is no specific staining for HHV-8 present. 


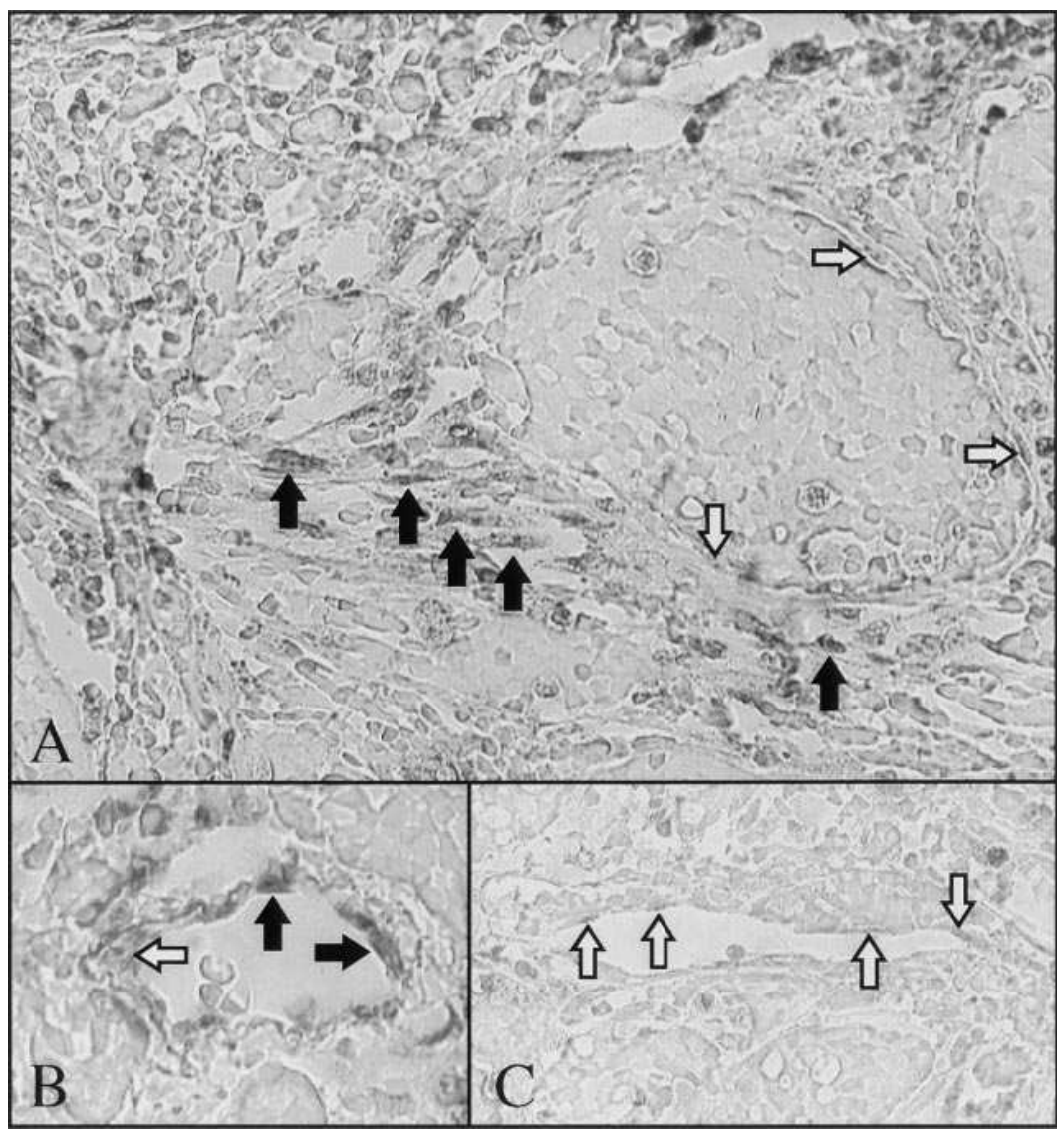

Figure 3. Pulmonary KS tissue samples processed for in situ PCR in the presence or absence of HHV-8 primers (limited digestion conditions with trypsin). (A) Spindle-shaped tumor cells in a pulmonary KS lesion pleural tissue were positive for HHV-8 (solid arrows). Of interest, the spindleshaped tumor cells appear to emerge from the edge of a large vessel that is lined with HHV-8-negative endothelial cells (open arrows). (B) A small pulmonary vessel lined with endothelial cells that were positive for HHV-8 (solid arrows), while other cells were negative (open arrow). (C) In a separate area of the same section of pulmonary KS, a small blood vessel is lined with endothelial cells that do not contain HHV-8 (open arrows). lining the alveolar spaces (two of two cases, Fig. $2 D$ ). The pulmonary macrophages in the alveolar spaces were negative for HHV-8, providing an internal control and demonstrating the specificity of the amplification (Fig. $2 \mathrm{D}$, inset). As in the cutaneous KS tissue samples, the amplification signal in the epithelioid and endothelial cells was limited to the nuclei. In situ PCR performed in the absence of Taq polymerase or primers produced a negative result (Fig. $2 E$ ).

Similar results were obtained using the limited digestion conditions with trypsin developed for in situ PCR (Fig. 3). The spindle-shaped tumor cells in pulmonary KS were positive for HHV-8 (Fig. $3 A$ ) and appear to emerge from the edge of a large blood vessel lined with endothelial cells that do not contain HHV-8. In comparison, small blood vessels in the same tissue section were either positive (Fig. $3 \mathrm{~B}$ ) or negative (Fig. 3 C) for HHV-8.

B cell lymphoma. We have recently described the clinical, light microscopic, and ultrastructural features of an EBV-negative, HHV-8-positive AIDS-related BCBL (22). To extend these initial observations, in situ PCR was performed on several tissue samples from various organs, including liver, lung, heart, and lymph node, that revealed HHV-8-positive cells in the mass of infiltrating lymphoid cells (Fig. $4 A$ ). Surrounding tissues including the hepatocytes of the liver and myocytes of the myocardium were negative for HHV-8 (data not shown). Once again, the specific signal was localized to the nuclei. In situ PCR performed on an adjacent tissue section in the absence of primers showed no specific signal (Fig. $4 B$ ).

While the in situ PCR-positive lymphoid cells appeared to be confined to the large, atypical malignant B cells (Fig. $4 A$ ), we sought more definitive evidence to support this light microscopic expression. Previous studies have demonstrated that the tumor cells in body cavity-based lymphomas are positive for EMA $(22,26)$. To determine whether or not the cells containing HHV-8 viral DNA sequences were also expressing EMA, we modified existing dual-staining protocols to combine in situ PCR and immunohistochemistry on the same tissue sections using a fluorescein-labeled antibody to EMA (27). As shown in Fig. 3, the green fluorescent cells (i.e., EMA-positive malignant tumor cells) are the same cells that are deeply stained with NBT/BCIP using the in situ PCR protocol (Fig. 4, $C$ and $D$, and $4, E$ and $F$; solid arrows). Other surrounding smaller, reactive-appearing lymphocytes in the area do not have nuclei with a positive HHV-8 signal, and likewise do not appear fluorescent with the anti-EMA antibody (Fig. 4, $C$ and $D$, and 4, $E$ and $F$; open arrows). Thus, by both light microscopic and dual staining (EMA and in situ PCR), the principle cell type that contains nuclear HHV-8 DNA-positive sequences is the malignant $\mathrm{B}$ cell population.

\section{Discussion}

Recent studies have indicated that the newly identified gamma-herpesvirus, HHV-8, may be the long sought etiological agent responsible for KS. PCR-based studies have confirmed the presence of HHV-8 DNA in samples from the four recognized forms of KS (AIDS-related, classical, iatrogenic, and African-endemic), as well as in AIDS-related BCBL and 


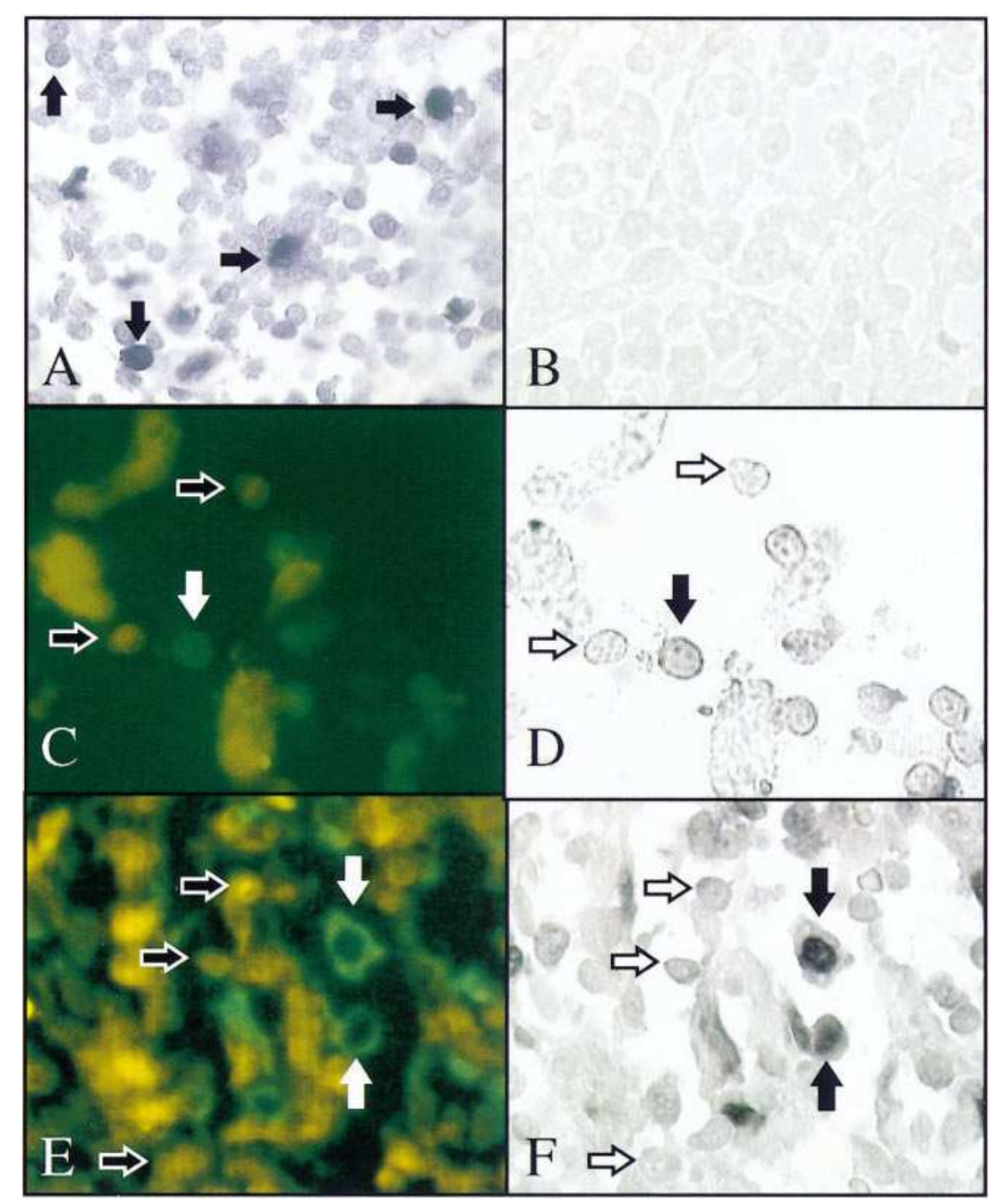

Figure 4. AIDS-related BCBL processed for in situ PCR in the presence or absence of HHV-8 primers. $(A)$ Many of the atypical-appearing lymphocytes in this tumor nodule from a liver specimen were positive after being stained deep purple by exposure to the chromagen NBT/BCIP (solid arrows), indicating the presence of $\mathrm{HHV}-8$, while other nuclei in smaller, reactive-type lymphocytes contained little to no staining with the chromagen. (B) In situ PCR of the tumor mass processed in the absence of $\mathrm{HHV}-8$ primers as a negative control. $(C)$ Dual staining was performed on several BCBL samples for EMA. After in situ PCR ( $\mathrm{HCl}$ and proteinase $\mathrm{K}$ digestion conditions), BCBL tissue samples were stained for detection of EMA using a fluorescein-labeled antibody. Both bright green fluorescein-labeled tumor cells (white arrow) as well as reactive lymphocytes that were not positive for EMA were present in the BCBL tissue sample (black arrows). (D) Tumor cells demonstrating positive staining for EMA were also positive for HHV-8 on in situ PCR (solid arrow). In contrast, the lymphocytes that were negative for EMA were also negative for HHV-8 (open arrows), indicating that these cells are reactive and not neoplastic. $(E)$ After in situ PCR (limited digestion conditions with trypsin), dual staining for the detection of EMA was performed using a fluorescein-labeled antibody. The fluorescein-labeled tumor cells (solid arrows) as well as the reactive lymphocytes that were not positive for EMA (open arrows) were present in this lymph node specimen from a BCBL patient. $(F)$ Tumor cells demonstrating positive staining for EMA were also positive for HHV-8 on in situ PCR (solid arrows). In contrast, the reactive lymphocytes that were negative for EMA were also negative for HHV-8 (open arrows). Use of limited digestion conditions with trypsin for in situ PCR with this sample resulted in improved tissue architecture compared with $C$ and $D$, which were treated with the more rigorous proteinase $\mathrm{K}$ digestion method. multicentric Castleman's disease (2-5, 28-31). However, these studies could not identify the cell types infected with HHV-8, which is critical to understanding the etiologic and pathophysiologic roles this virus may play in KS. Identification of the virus in the actual neoplastic cellular elements of the $\mathrm{KS}$, AIDS-related BCBL, and multicentric Castleman's disease is an essential element in attempting to distinguish between an association of HHV-8 (i.e., preferred passenger), and the demonstration of a more direct cause:effect type of relationship (20).

The novel findings presented in this report are that HHV-8 was identified in the early, patch-stage lesions of KS localizing to endothelial cells and spindle-shaped tumor cells using in situ PCR. Moreover, in the advanced lesions, besides these mesenchymal cells, HHV-8 was also present in the overlying keratinocytes (four of five) and in admixed eccrine duct epithelial cells within skin. Positive keratinocytes were limited to the epidermis directly above the lesion with keratinocytes in perilesional areas negative for $\mathrm{HHV}-8$ sequences. The importance of HHV-8 infection of the keratinocytes is currently unknown. However, it is not surprising that epithelial cells like kerati- nocytes are positive for HHV-8 considering our results showing HHV-8 in the epithelioid cells lining the alveoli (i.e., pneumocytes), epithelial cells of eccrine ducts, and studies from others indicating HHV-8 in human urothelial cells (32). We also have evidence of transfer of HHV-8 infection from isolated KS tumor cells to an embryonal kidney epithelial cell line, 293 cells (23). Only in one of four $(25 \%)$ patch-stage lesions were the keratinocytes positive for HHV-8, compared with $80 \%$ of plaque/tumor-stage biopsies. This suggests that keratinocytes are not a primary target for infection by HHV-8, but may become secondarily infected in the skin.

In situ PCR does have the potential problem of nonspecific incorporation of labeled nucleotides into PCR products produced as part of nonspecific DNA repair pathways that can lead to false positive results $(19,33)$. Our results using normal human skin under identical conditions as with the KS lesions demonstrated no amplification, as shown in Fig. $1, C$ and $D$. This, in combination with control samples of in situ PCR in the absence of Taq polymerase and/or primers, indicate that nonspecific pathways of PCR amplification were not responsible 
for our results. In addition, our results were reproducible with PCR in situ hybridization; however, the signal was weaker than in in situ PCR in some cases.

In the previously published reports, serial tissue sections were used for in situ hybridization and immunohistochemical staining to show that similar cells to those containing HHV-8 sequences were also positive for particular surface markers, such as CD34. In this report, we use a protocol combining in situ PCR and immunostaining on the same tissue section using fluorescein-conjugated EMA antibodies. With this technique, the lymphoid cells in an AIDS-related BCBL were shown to be both EMA-positive tumor cells and HHV-8-positive, which was in contrast with the EMA-negative reactive lymphocytes, which did not contain HHV-8 by in situ PCR. The colocalization of HHV-8 DNA-positive nuclei to malignant lymphoid EMA-positive cells is consistent with our earlier ultrastructural observations that confined intranuclear viral particles consistent with herpes virions to the neoplastic lymphoid cells (22). Experiments also attempted dual labeling of the KS tumor cells with fluorescein-labeled CD34 antibody, but were unsuccessful. This is likely due to destruction of the antigen during preparation of the tissue and PCR amplification. As mentioned above, if HHV-8 only represented an opportunistic viral infection, it would probably have been more widely distributed amongst benign and malignant lymphoid cells. The striking one-to-one correlation in which HHV-8 is preferentially contained within the malignant $B$ cells provides new evidence for a causal link in the disease process. Obviously, additional studies are indicated to more precisely determine the molecular basis for the role of HHV-8 in the transformation process, although several candidate gene sequences have recently been suggested in this regard $(34,35)$.

To date, data from a variety of laboratories indicates that HHV-8 may be the etiologic agent of KS and not a ubiquitous virus casually associated with this disease. However, this is still a controversial issue with several other laboratories providing evidence of HHV-8 in tissues from normal donors and patients without $\mathrm{KS}(9,32,36,37)$. In this report, we demonstrate HHV-8 in the neoplastic cellular elements of both KS and AIDS-related BCBL. We have also identified HHV-8 in tumor cells in the earliest lesions of KS. This data indicates a role for HHV-8 in the development of KS, and would support the notion that HHV-8 is an etiologic agent or cofactor in the production of KS lesions. However, the current in situ PCR studies, while supporting an etiological role for HHV-8 in KS, cannot entirely substitute for more definitive epidemiologically based studies $(38,39)$. More definitive studies are clearly indicated to determine how widespread HHV-8 is in the general population. Until it is demonstrated that injection of HHV-8 in an appropriate animal model system can cause KS lesions to develop, caution is still warranted in assuming this is the etiological agent in KS (40). Given the growing body of data supporting a key role for HHV-8 in the etiopathogenesis of $\mathrm{KS}$, experiments designed to directly examine the cause-effect relationship are currently underway and the results will undoubtedly be forthcoming in the near future.

\section{Acknowledgments}

This work was supported in part by grants for the National Institutes of Health (AR-40488, CA-64416, and CA-70057) to B.J. Nickoloff.

\section{References}

1. Beral, V. 1991. Epidemiology of Kaposi's sarcoma. Cancer Surv. 10:5-22.

2. Chang, Y., E. Cesarman, M.S. Pessin, F. Lee, J. Culpepper, D.M. Knowles, and P.S. Moore. 1994. Identification of herpesvirus-like DNA sequences in AIDS-associated Kaposi's sarcoma. Science (Wash. DC). 266:18651869.

3. Moore, P.S., and Y. Chang. 1995. Detection of herpesvirus-like DNA sequences in Kaposi's sarcoma in patients with and without HIV infection. $N$. Engl. J. Med. 332:1181-1185.

4. Huang, Y.Q., J.J. Li, M.H. Kaplan, B. Poiesz, E. Katabira, W.C. Zhang, D. Feiner, and A.E. Friedman-Kien. 1995. Human herpesvirus-like nucleic acid in various forms of Kaposi's sarcoma. Lancet. 345:759-761.

5. Dupin, N., M. Grandadam, V. Calvez, I. Gorin, J.T. Aubin, S. Havard, F. Lamy, M. Leibowitch, J.M. Huraux, J.P. Escande, and H. Agut. 1995. Herpesvirus-like DNA sequences in patients with Mediterranean Kaposi's sarcoma. Lancet. 345:761-762.

6. Gao, S.J., L. Kingsley, M. Li, W. Zheng, C. Parravicini, J. Ziegler, R. Newton, C.R. Rinaldo, A. Saah, J. Phair, et al. 1996. KSHV antibodies among Americans, Italians, and Ugandans with and without Kaposi's sarcoma. Nat. Med. 2:925-928.

7. Gao, S.J., L. Kingsley, D.R. Hoover, T.J. Spira, C.R. Rinaldo, A. Saah, J Phair, R. Detels, P. Parry, Y. Chang, and P.S. Moore. 1996. Seroconversion to antibodies against Kaposi's sarcoma-associated herpesvirus-related latent nuclear antigens before the development of Kaposi's sarcoma. N. Engl. J. Med. 335:233-241.

8. Kedes, D.H., E. Operskalski, M. Busch, R. Kohn, J. Flood, and D. Ganem. 1996. The seroepidemiology of human herpesvirus 8 (Kaposi's sarcoma-associated herpesvirus) - distribution of infection in KS risk groups and evidence for sexual transmission. Nat. Med. 2:918-924.

9. Lennette, E.T., D.J. Blackbourn, and J.A. Levy. 1996. Antibodies to human herpesvirus type 8 in the general population and in Kaposi's sarcoma patients. Lancet. 348:858-861.

10. Weiss, R.A. 1996. Human herpesvirus 8 in lymphoma and Kaposi's sarcoma: now the virus can be propagated. Nat. Med. 2:277-278.

11. O'Leary, J.J. 1996. Seeking the cause of Kaposi's sarcoma. Nat. Med. 2: 862-863.

12. Cohen, J. 1995. Controversy: is KS really caused by new herpesvirus? Science (Wash. DC). 268:1847-1848.

13. Roizman, B. 1995. New viral footprints in Kaposi's sarcoma. N. Engl. J. Med. 332:1227-1228.

14. Decker, L.L., P. Shankar, G. Khan, R.B. Freeman, B.J. Dezube, J. Lieberman, and D.A. Thorley-Lawson. 1996. The Kaposi sarcoma-associated herpesvirus (KSHV) is present as an intact latent genome in KS tissue but replicates in the peripheral blood mononuclear cells of KS patients. J. Exp. Med. 184:283-288.

15. Zhong, W.D., H. Wang, B. Herndier, and D. Ganem. 1996. Restricted expression of Kaposi sarcoma-associated herpesvirus (human herpesvirus 8) genes in Kaposi sarcoma. Proc. Natl. Acad. Sci. USA. 93:6641-6646.

16. Nickoloff, B.J., and K.E. Foreman. 1996. Charting a new course through the chaos of KS (Kaposi's sarcoma). Am. J. Pathol. 148:1323-1329.

17. Li, J.J., Y.Q. Huang, C.J. Cockerell, and A.E. Friedman-Kien. 1996. Localization of human herpes-like virus type 8 in vascular endothelial cells and perivascular spindle-shaped cells of Kaposi's sarcoma lesions by in situ hybridization. Am. J. Pathol. 148:1741-1748.

18. Weiss, L.M., and L.A. Movahed. 1989. In situ demonstration of EpsteinBarr viral genomes in viral-associated B cell lymphoproliferations. Am. J. Pathol. 134:651-659.

19. Komminoth, P., and A.A. Long. 1993. In-situ polymerase chain reaction. An overview of methods, applications and limitations of a new molecular technique. Virchows Archiv. B Cell Pathol. Incl. Mol. Pathol. 64:67-73.

20. Weiss, L.M., and K.L. Chang. 1996. Association of the Epstein-Barr virus with hematolymphoid neoplasia. Adv. Anat. Pathol. 3:1-15.

21. Boshoff, C., T.F. Schulz, M.M. Kennedy, A.K. Graham, C. Fisher, A. Thomas, J.O. McGee, R.A. Weiss, and J.J. O'Leary. 1995. Kaposi's sarcomaassociated herpesvirus infects endothelial and spindle cells. Nat. Med. 1:12741278 .

22. Duggan, J., E. Hsi, K.E. Foreman, H. Aronow, C. Kauffman, and B.J. Nickoloff. 1996. HHV-8 in cardiac lymphoma in an AIDS patient. Infect. Dis. Soc. Am. 185. (Abstr.)

23. Foreman, K.E., J. Friborg, W. Kong, C. Woffendin, P.J. Polverini, B.J. Nickoloff, and G.J. Nabel. 1997. Propagation of a human herpesvirus from AIDS-associated Kaposi's sarcoma. N. Engl. J. Med. 336:163-171.

24. Long, A.A., P. Komminoth, E. Lee, and H.J. Wolfe. 1993. Comparison of indirect and direct in-situ polymerase chain reaction in cell preparations and tissue sections. Detection of viral DNA, gene rearrangements and chromosomal translocations. Histochemistry. 99:151-162.

25. Nuovo, G.J. 1994. PCR in situ Hybridization. Protocols and Applications. Raven Press, New York. pp. 54-246.

26. Ansari, M.Q., D.B. Dawson, R. Nador, C. Rutherford, N.R. Schneider, M.J. Latimer, L. Picker, D.M. Knowles, and R.W. McKenna. 1996. Primary body cavity-based AIDS-related lymphomas. Am. J. Clin. Pathol. 105:221-229. 
27. Gressens, P., and J.R. Martin. 1994. HSV-2 DNA persistence in astrocytes of the trigeminal root entry zone: double labeling by in situ PCR and immunohistochemistry. J. Neuropathol. Exp. Neurol. 53:127-135.

28. de Lellis, L., M. Fabris, E. Cassai, A. Corallini, G. Giraldo, C. Feo, and P. Monini. 1995. Herpesvirus-like DNA sequences in non-AIDS Kaposi's sarcoma. J. Infect. Dis. 172:1605-1607.

29. Buonaguro, F.M., M.L. Tornesello, E. Beth-Giraldo, A. Hatzakis, N. Mueller, R. Downing, B. Biryamwaho, S.D. Sempala, and G. Giraldo. 1996. Herpesvirus-like DNA sequences detected in endemic, classic, iatrogenic and epidemic Kaposi's sarcoma (KS) biopsies. Int. J. Cancer. 65:25-28.

30. Cesarman, E., Y. Chang, P.S. Moore, J.W. Said, and D.M. Knowles. 1995. Kaposi's sarcoma-associated herpesvirus-like DNA sequences in AIDSrelated body-cavity-based lymphomas. N. Engl. J. Med. 332:1186-1191.

31. Soulier, J., L. Grollet, E. Oksenhendler, P. Cacoub, D. Cazals-Hatem, P. Babinet, M.F. d'Agay, J.P. Clauvel, M. Raphael, L. Degos, and F. Sigaux. 1995. Kaposi's sarcoma-associated herpesvirus-like DNA sequences in multicentric Castleman's disease. Blood. 86:1276-1280.

32. Monini, P., L. de Lellis, M. Fabris, F. Rigolin, and E. Cassai. 1996. Kaposi's sarcoma-associated herpesvirus DNA sequences in prostate tissue and human semen. N. Engl. J. Med. 334:1168-1172.

33. Sallstrom, J.F., I. Zehbe, M. Alemi, and E. Wilander. 1993. Pitfalls of $i n$ situ polymerase chain reaction (PCR) using direct incorporation of labelled nucleotides. Anticancer Res. 13:1153-1154.

34. Moore, P.S., C. Boshoff, R.A. Weiss, and Y. Chang. 1996. Molecular mimicry of human cytokine and cytokine response pathway genes by KSHV. Science (Wash. DC). 274:1739-1744.

35. Cesarman, E., R.G. Nador, F. Bai, R.A. Bohenzky, J.J. Russo, P.S Moore, Y. Chang, and D.M. Knowles. 1996. Kaposi's sarcoma-associated herpesvirus contains $\mathrm{G}$ protein-coupled receptor and cyclin D homologs which are expressed in Kaposi's sarcoma and malignant lymphoma. J. Virol. 70:82188223.

36. Rady, P.L., A. Yen, J.L. Rollefson, I. Orengo, S. Bruce, T.K. Hughes, and S.K. Tyring. 1995. Herpesvirus-like DNA sequences in non-Kaposi's sarcoma skin lesions of transplant patients. Lancet. 345:1339-1340.

37. Sander, C.A., M. Simon, U. Puchta, M. Raffeld, and P. Kind. 1996. HHV-8 in lymphoproliferative lesions in skin. Lancet. 348:475-476.

38. Ganem, D. 1996. Human herpesvirus 8 and the biology of Kaposi's sarcoma. Semin. Virol. 7:325-332.

39. Levy, J.A. 1997. Three new human herpesviruses (HHV-6, 7, and 8). Lancet. 349:558-562.

40. Fredericks, D.N., and D.A. Relman. 1996. Sequence-based evidence of microbial disease causation: when Koch's postulates don’t fit. J. NIH Res. 8:39-44. 